\title{
Ascophyllum nodosum extract improves leaf thermoregulation by reducing stomatal sensitivity to VPD in Vitis vinifera $L$.
}

\author{
Sergio Tombesi ${ }^{1}$ (D) $\cdot$ Tommaso Frioni $^{1} \cdot$ Paolo Sabbatini $^{2} \cdot$ Stefano Poni $^{1} \cdot$ Alberto Palliotti $^{3}$
}

Received: 8 June 2020 / Revised and accepted: 11 November 2020 / Published online: 26 November 2020

(C) The Author(s) 2020

\begin{abstract}
Climate change scenarios and the need of sustainable tools to reduce global warming impact on agriculture have led to the formulation of a large number of natural products or biostimulants that should increase plant resilience to abiotic stress. Ascophyllum nodosum (AN) extract is one of the most studied biostimulants to increase tolerance to drought stress, but the physiological mechanism underlying its action is still poorly understood. The aim of the present work was to determine AN extract impact on grapevine gas exchange under well-watered and water stress conditions and to examine its mode of action under stress (light and temperature). AN caused a slight increase in stomatal conductance that resulted in an increase of water plant conductivity to atmosphere. Increased transpiration induced by AN improved leaf thermoregulation, facilitating vine recovery after a stress period. AN increased transpiration through a reduction of stomatal sensitivity to VPD. AN action on stomata regulation indicated that this biostimulant could be a new potential tool to limit leaf damage during events of extreme temperature, even when they are not combined with water stress conditions.
\end{abstract}

Keywords Stomata regulation $\cdot$ Biostimulant $\cdot$ Grapevine $\cdot$ Light stress $\cdot$ Temperature stress'

\section{Introduction}

Climate change scenarios forecast the increase of mean temperature over the next decades along with increased frequency of extreme events such as floods, severe droughts, and hot spells during the summer (IPCC 2013). Such climate modifications are a challenge for agriculture; therefore, the development of new tools that can reduce the impact of climate extremes on plant productivity has recently gained large attention (Raza et al. 2019).

Plant biostimulants, defined as "formulated products of biological origin that improve plant productivity as a consequence of the novel or emergent properties of the complex of constituents, and not as a sole consequence of the presence

Sergio Tombesi

sergio.tombesi@unicatt.it

1 Department of Sustainable Crop Production, Università Cattolica del Sacro Cuore, Via Emilia Parmense 84, 29122 Piacenza, Italy

2 Department of Horticulture, Michigan State University, 1066 Bogue Street, East Lansing, MI 48824, USA

3 Department of Agricultural, Food and Environmental Sciences, Università degli Studi di Perugia, Borgo 20 Giugno 74, 06154 Perugia, Italy of known essential plant nutrients, plant growth regulators, or plant protective compounds" (Yakhin et al. 2017), are alternative tools to enhance plant nutrition and to improve plant resilience to environmental stresses (du Jardin 2015; De Pascale et al. 2017). Among biostimulants obtained from seaweeds, those from Ascophyllum nodosum (AN) extracts are the most investigated (Shukla et al. 2019). Furthermore to the positive effects on fruit quality of many horticultural species (du Jardin 2015), AN has been indicated to alleviate drought stress in many species (for a review, see Shukla et al. (2019)), yet the physiological mechanism underpinning the increased drought stress tolerance is not clear.

In grapevine, Ascophyllum nodosum extract has been reported to improve vegetative growth and grape quality by increasing the accumulation of anthocyanins and phenolics (Norrie et al. 2002; Sabir et al. 2014; Popescu and Popescu 2014; Frioni et al. 2018, 2019; Salvi et al. 2019). AN extract has been reported to alleviate drought stress in Vitis vinifera (Frioni et al. 2019; Salvi et al. 2019, 2020) but the physiological mechanism of action is still unclear. Indeed, AN extract was hypothesized to increase solutes affecting plant osmoregulation capacity during water stress (Khan et al. 2009; Di Stasio et al. 2018) and to provide precursors that can contribute to the protection of leaf tissues against reactive oxygen species (ROS) formed during stress (Laetitia et al. 2010). 
Drought stress is a combination of multiple stresses: water, light, and temperature (Palliotti et al. 2009). Data reported in literature about AN extract upregulation of stomatal conductance makes it a possible candidate to improve thermoregulation even when light and temperature stresses occur under well-watered conditions. We hypothesized that alkaline AN extract could increase grapevine transpiration improving thermoregulation with positive consequences on gas exchange recovering after stress occurrence.

The aim of the present work was to determine the effect of an alkaline AN extract on the gas exchange of $V$. vinifera grapevines under well-watered and water stress condition. Furthermore, we aimed to test the effect of AN in alleviating light and temperature stress components under well-watered condition and water stress.

\section{Materials and methods}

\section{Water stress experiment}

The experiment was carried out in 2015 in an outdoor space at the Department of Agricultural, Food and Environmental Sciences, University of Perugia, located in the urban area of the city of Perugia, Central Italy $\left(43^{\circ} 10^{\prime} 30^{\prime \prime} \mathrm{N} 12^{\circ} 39^{\prime} 45^{\prime \prime} \mathrm{E}\right.$, $405 \mathrm{~m}$ a.s.l). Twenty 60 -L pots were filled with loamy soil having a field capacity of $30.2 \%$ [(volume water/volume soil $) \times 100$ ] and a wilting point of $16.7 \%$. Each pot contained a 5 -year-old vine cv. Sangiovese (clone VCR30, grafted on 1103 Paulsen). Vines were spur-pruned in winter with three spurs carrying two buds each. Each bud bore a mean of 1.5 cluster in the season when the experiment was carried out. During growth, developing shoots were directed upright using suitable stakes. Control pots were maintained at field capacity throughout the experiment by an automated water-supply system providing water to each pot for $1 \mathrm{~min}$ three times per day (08:00 h, 13:00 h, and 18:00 h, $6 \mathrm{~L}$ per vine per day). Pest control was carried out based on expertise and as per local standards. On days-of-year (DOY) 174 and 181, half of the vines were subjected to foliar applications (AN) of Acadian Marine Plant Extract Powder (Acadian Seaplants Limited). The product was sprayed at the rate of $3 \mathrm{~g} \mathrm{plant}^{-1}$, which had already been tested for grapevines and other species (Frioni et al. 2018; Salvi et al. 2019). To improve uniformity of the spray application, for every $100 \mathrm{~mL}$ of solution, two drops of surfactant (Tween 20) were added to the solution. The other ten vines were assigned to the control treatment (Control) and treated with multiple water sprays at the same time of the AN application, according to Faurie et al. (2009) and Jayaraman et al. (2011). The full-canopy sprays were performed at 08:00 $\mathrm{h}$.

On 10 vines (WS), 5 from the Control treatment and 5 from AN treatment, irrigation was withheld on 31 June (DOY 182) to 5 July (DOY 186). On July 6, irrigation was resumed. The remaining vines were kept well irrigated throughout the whole experiment (WW).

\section{Light and temperature stress experiment}

To test the effect $\mathrm{AN}$ on leaves under high temperature and light regime, we kept leaves artificially horizontally in order to expose them to higher solar irradiance than in naturally oriented leaves during the central hours of the day when microclimatic conditions are the most stressful for the leaf. On July 3 (DOY 184), one leaf per vine was kept artificially horizontal by placing a nylon wire support below the leaf blade, taking care that the leaf blade did not touch any metal part of the support to prevent any sunburn caused by the metal heating.

\section{Gas exchange PSII efficiency measurements}

Stomatal conductance $\left(\mathrm{g}_{\mathrm{s}}\right)$ and net photosynthesis $\left(\mathrm{P}_{\mathrm{n}}\right)$ measurements were carried out on adult primary leaves grown between the 4th and the 10th nodes from the shoot base and after DOY 184 on horizontal leaves and on unconditioned leaves ( 3 leaves per treatment, 1 per vine). Measurements were carried out between 12:00 am and 1:00 pm, from 30 June until 8 July on one representative leaf sampled from 3 vines per treatment using an open gas exchange system (ADC-System, LCA-3, Hoddesdon, UK) equipped with a Parkinson leaf chamber $\left(11.2 \mathrm{~cm}^{2}\right)$. Measurements were performed under saturating light conditions (PPFD > $1200 \mu \mathrm{mol}$ photons $\mathrm{m}^{-2} \mathrm{~s}^{-1}$ ). Photosystem II efficiency was tested through leaf chlorophyll fluorescence parameters taken on the same leaves previously sampled for gas exchange. Chlorophyll $a$ fluorescence was measured with a lightweight portable continuous excitation fluorimeter (Handy-PEA, Hansatech Institute Ltd, UK). Dark adaptation was achieved by covering the sample area to be analyzed with a small, lightweight leaf clip for at least $20 \mathrm{~min}$. The small shutter plate of the clip was then opened, and the dark-adapted leaf tissue was exposed to an actinic light flash (wavelength of $650 \mathrm{~nm}$, intensity $>3000 \mu \mathrm{mol}$ photons $\mathrm{m}^{-2} \mathrm{~s}^{-1}$ ). The instrument provides the $F_{v} / F_{m}$ ratio, which is a widely accepted indicator of the maximum efficiency of PSII, where $F_{m}$ is the fluorescence maximum over the induction curve. $\mathrm{F} v$ (variable fluorescence) was calculated as the difference between $F_{m}$ and $F_{o}$, where $F_{o}$ is the ground fluorescence (Strasser et al. 1995). Leaf temperature was measured with an infrared thermometer (Mod. TM909L9, Assi-control, Italy).

\section{Water potential measurements}

On the same leaves processed for gas exchange, chlorophyll fluorescence, and temperature measurements, leaf water 


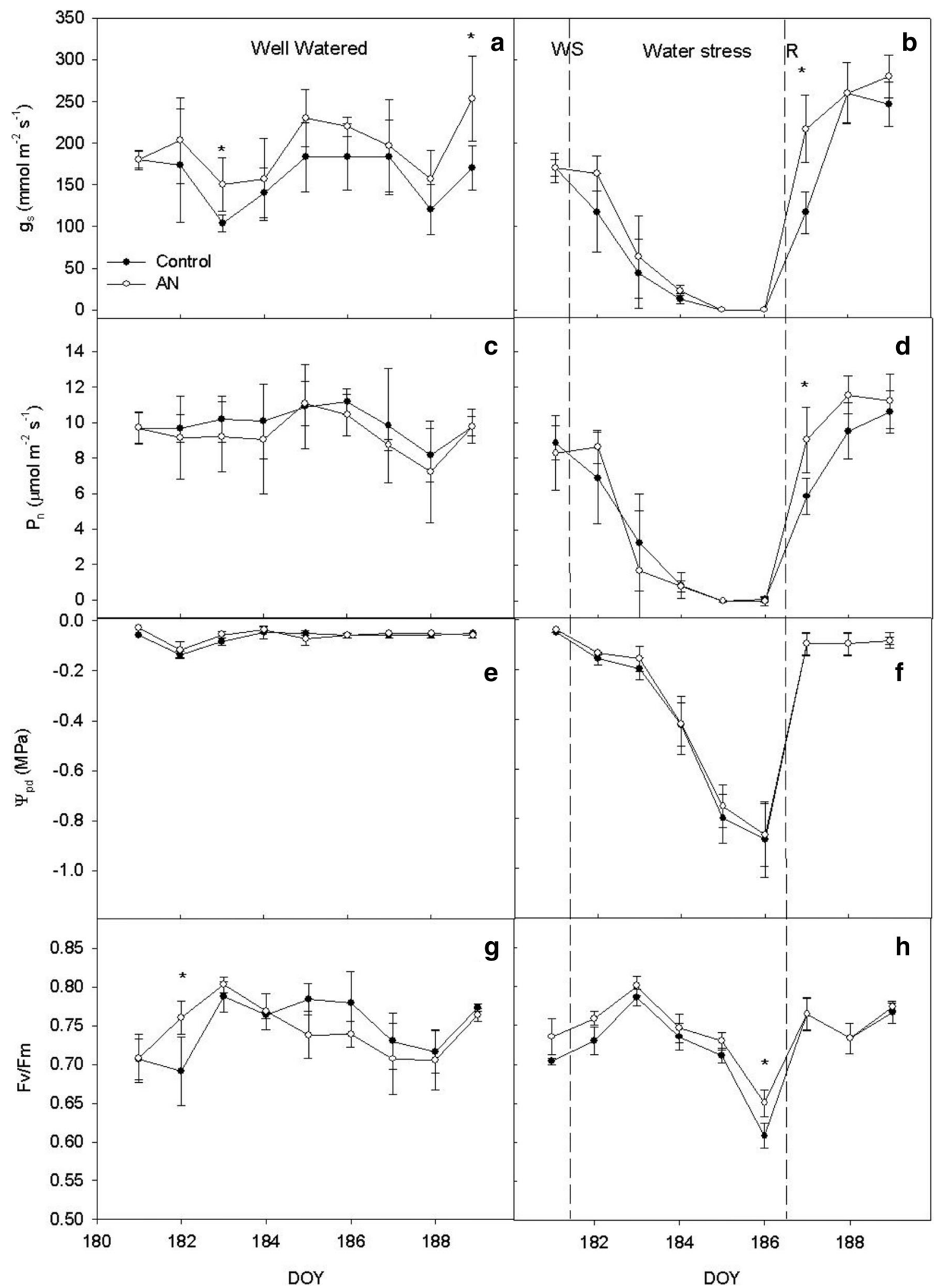

Fig. 1 Stomatal conductance $\left(\mathrm{g}_{\mathrm{s}}\right)$, net photosynthesis $\left(\mathrm{P}_{\mathrm{n}}\right)$, pre-dawn water potential $\left(\Psi_{\mathrm{pd}}\right)$, and $\mathrm{F}_{\mathrm{v}} / \mathrm{F}_{\mathrm{m}}$ recorded on mature leaves (unconditioned) of well-watered (a, c, e, and $\mathbf{g}$, respectively) and water stress vines $(\mathbf{b}, \mathbf{d}, \mathbf{f}$,

potential ( $\left.\Psi_{\text {leaf }}\right)$ was measured by a pressure chamber (Soilmoisture Corp, USA). and $\mathbf{h}$ ) during the experiment. Each point is the mean of three vine $\pm \mathrm{SE}$. Points marked by asterisk are different per $p<0.05$ (Tukey test)

Stem water potential $\left(\Psi_{\text {stem }}\right)$ was measured over the same days and daytime of gas exchange on each vine used for gas 
exchange measurements on one mature leaf (different from those used for $\Psi_{\text {leaf }}$ ) that had been wrapped in plastic film and aluminum foil $2 \mathrm{~h}$ prior to the measurements. Water potential values measured at 4:00 am are reported as pre-dawn water potential $\left(\Psi_{\mathrm{pd}}\right)$. Plant hydraulic conductance was calculated according to Sperry and Pockman (1993) as:

$\mathrm{K}_{\text {plant }}=\mathrm{E} /\left(\Psi_{\mathrm{pd}}-\Psi_{\text {leaf }}\right)$

where $E$ is the leaf transpiration, $\Psi_{p d}$ is pre-dawn water potential, and $\Psi_{\text {leaf }}$ is leaf water potential.

Data were analyzed by linear and non-linear regression analyses using Sigmaplot 8.0 (SystatSoftware Inc., USA), and $\mathrm{R}^{2}$ significance was assessed by ANOVA. In particular, non-linear regressions were used for the relationship between $g_{s}$ and $P_{n}$ vs. $\Psi_{\text {stem }}, P_{n}$ vs. $g_{s}$, and $K_{\text {plant }}$ vs. $\Psi_{\text {stem }}$. Linear regression was used for the relationship between E and VPD. Treatments were analyzed by one-way ANOVA (Fig. 1) and two-way ANOVA with significance level set at 0.05 ; means were then separated by Tukey's $w$-procedure at $p=0.05$.

\section{Results}

Stomatal conductance $\left(\mathrm{g}_{\mathrm{s}}\right)$ ranged between 100 and $250 \mathrm{mmol}$ $\mathrm{m}^{-2} \mathrm{~s}^{-1}$ under well-watered conditions (Fig. 1a). g $\mathrm{s}_{\mathrm{s}}$ was generally higher in AN treated grapevine, but it was significant ( $p$ $<0.05$ ) only on DOY 183 and 189. Under water stress, $g_{s}$ declined over the dry-down period without significant differences between treatments, reaching complete stomatal closure on DOY 185 (Fig. 1b). The day after rewatering, $g_{s}$ of AN vines promptly recovered to levels similar to the WW treatments. Conversely, at DOY 187 , the recovery was partial in WS Control vines and $g_{s}$ values were lower than those of $A N$ vines and $W W$ vines. Mean net photosynthesis $\left(P_{n}\right)$ was constant in the range $7-11 \mu \mathrm{mol} \mathrm{m}^{-2} \mathrm{~s}^{-1}$ in WW vines, without significant differences between treatments (Fig. 1c). In WS vines, $P_{n}$ decreased reaching slightly negative values ($0.03 \pm 0.005 \mu \mathrm{mol} \mathrm{m}^{-2} \mathrm{~s}^{-1}$ ) on DOY 186 (Fig. 1d). After rewatering, on DOY $187, \mathrm{P}_{\mathrm{n}}$ of AN vines fully recovered to the values observed during pre-stress while Control vines still had, on the same date, significantly lower $P_{n}$ values. The difference between the two treatments was reduced over the next 2 days until reaching non-significance. Pre-dawn leaf water potential $\left(\Psi_{\mathrm{pd}}\right)$ was steady between -0.1 and $-0.15 \mathrm{MPa}$ in WW treatments while it ranged between -0.1 and $-0.88 \mathrm{MPa}$ in WS treatment (Fig. 1E and F). There were no significant differences for $\Psi_{\mathrm{pd}}$ between Control and AN treatments during the whole experiment. In both WS treatments, $\Psi_{\mathrm{pd}}$ immediately recovered few hours after rewatering, reaching the same values of WW treatments at DOY 187. $\mathrm{F}_{\mathrm{v}} / \mathrm{F}_{\mathrm{m}}$ ranged between 0.69 and 0.80 in WW treatments with no significant differences between treatments, except at DOY 182 when WW AN had higher $F_{v} / F_{m}$ than WW Control (Fig. 1G). In WS vines, $F_{v} / F_{m}$ ranged between 0.60 and $0.80 ; F_{v} / F_{m}$ was slightly higher in AN than in Control vines and on DOY 186 such difference was significant (Fig. 1H). After rewatering, $\mathrm{F}_{\mathrm{v}} / \mathrm{F}_{\mathrm{m}}$ completely recovered in both treatment reaching values similar to WW treatments.

Midday stem water potential $\left(\Psi_{\text {stem }}\right)$ was significantly affected by water regime but the effect of treatment was not significant; the interaction between water regime and $\mathrm{AN}$ treatment was significant (Fig. 2). In WW vines, $\Psi_{\text {stem }}$ was similar between Control and AN, except at DOY 181 and 182. During WS, AN $\Psi_{\text {stem }}$ was lower than in Control during the
Fig. 2 Stem water potential at midday $\left(\Psi_{\text {stem }}\right)$ during the experiment in Control and AN vines under well-watered (WW) and water stress (WS). Each point is the mean of three vine \pm SE. Points marked by different letters are different per $p<0.05$ (twoway ANOVA and Tukey test)

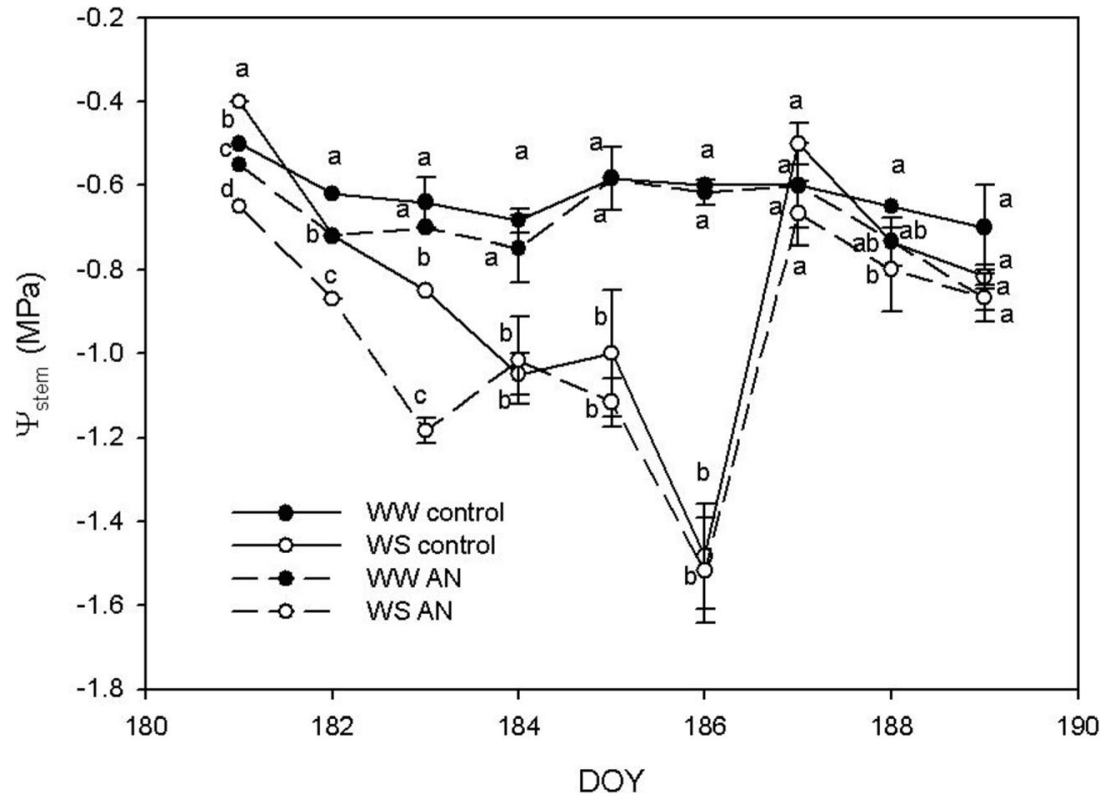


early stages of WS up to DOY 183; thereafter, they followed a similar trend without significant differences.

Stomatal conductance was correlated to $\Psi_{\text {stem }}$ by a sigmoidal curve; maximum $g_{s}$ was at $\Psi_{\text {stem }}$ values higher than - 0.7 MPa in Control, whereas AN retained higher $g_{\mathrm{s}}$ for less negative $\Psi_{\text {stem }}$ (Fig. 3A). Stomatal closure was at about - 0.9 $\mathrm{MPa}$ in Control while it was at $-1.2 \mathrm{MPa}$ in AN. $\mathrm{P}_{\mathrm{n}}$ was correlated with $\Psi_{\text {stem }}$ (Fig. 3B). In Control, maximum $P_{n}$ was observed at $\Psi_{\text {stem }}$ higher than $-0.7 \mathrm{MPa}$. Values of $\mathrm{P}_{\mathrm{n}}$ close to 0 were recorded at $\Psi_{\text {stem }}$ values close to -0.8 and - 1.1 MPa in Control and AN vines, respectively. $\mathrm{P}_{\mathrm{n}}$ during recovery was like that recorded during the previous part of the experiment in the same range of $\Psi_{\text {stem }}$.

$P_{n}$ was correlated to $g_{s}$ in both treatment by similar quadratic models (Fig. 4). The relationship was almost linear at $\mathrm{g}_{\mathrm{s}}$ between 0 and $150 \mathrm{mmol} \mathrm{m}^{-2} \mathrm{~s}^{-1}$. At higher $\mathrm{g}_{\mathrm{s}}$ values, the increase of $P_{n}$ was much more limited and the relationship plateaued.
Plant hydraulic conductance $\left(\mathrm{K}_{\text {plant }}\right)$ decreased with $\Psi_{\text {stem }}$ becoming more negative (Fig. 5). AN vines had $\mathrm{K}_{\text {plant }}$ values slightly elevated than Control vines, in particular when the $\Psi_{\text {stem }}$ was higher than $-0.7 \mathrm{MPa}$. $\mathrm{K}_{\text {plant }}$ after rewatering was higher than that recorded at the same $\Psi_{\text {stem }}$ levels in WW vines and in WS vines before rewatering.

Under WW conditions, the effect of the orientation of leaves (horizontal vs unconditioned) and the interaction between leaf orientation and AN treatment on $\mathrm{g}_{\mathrm{s}}$ was significant (Fig. 6a). Untreated unconditioned leaves had much higher $\mathrm{g}_{\mathrm{s}}$ than leaves kept horizontal (Fig. 6a). Horizontal AN leaves had a $g_{s}$ similar to that of unconditioned leaves except for DOY 185 and 189 when it was lower. $\mathrm{P}_{\mathrm{n}}$ was significantly influenced by the leaf orientation and by the interaction between leaf orientation and AN treatment (Fig. 6b). $P_{n}$ in unconditioned leaves was always higher than in horizontal Control leaves. $\mathrm{P}_{\mathrm{n}}$ in horizontal $\mathrm{AN}$ leaves was lower than in
Fig. 3 Relationship between stomatal conductance $\left(\mathrm{g}_{\mathrm{s}}\right)$ and stem water potential at midday $\left(-\Psi_{\text {stem }}\right)$ in WW and WS Control $(\mathrm{y}=0.17 /(1+\exp (-(\mathrm{x}-0.80) /$ $\left.-0.05, \mathrm{R}^{2}=0.73 p<0.0001\right)$ and AN $(\mathrm{y}=0.37 /(1+\exp (-(\mathrm{x}-0.62) /$ $\left.-0.22, \mathrm{R}^{2}=0.68 p<0.0001\right)$ (a) and relationship between net photosynthesis $\left(\mathrm{P}_{\mathrm{n}}\right)$ and stem water potential at midday $\left(-\Psi_{\text {stem }}\right)$ in WW and WS Control $(\mathrm{y}=9.91 /(1+\exp (-(\mathrm{x}-0.79) /$ $\left.-0.03, R^{2}=0.85 p<0.0001\right)$ and $\mathrm{AN}(\mathrm{y}=11.96 /(1+\exp (-(\mathrm{x}-$ $0.84) /-0.14, \mathrm{R}^{2}=0.74 p<$ 0.0001 ) vines (unconditioned leaves) excluding data point collected after rewatering (b)

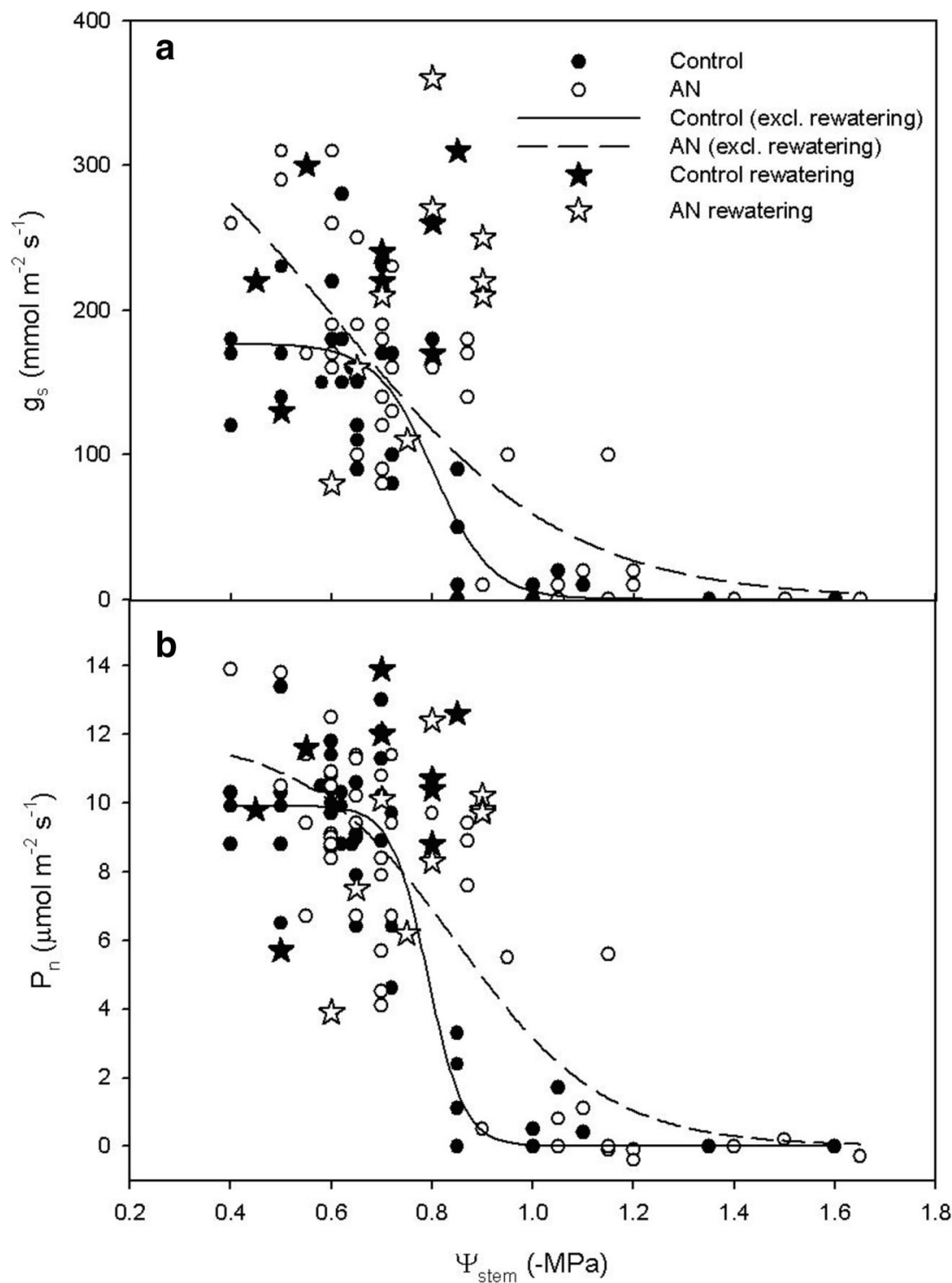


Fig. 4 Relationship between net photosynthesis $\left(\mathrm{P}_{\mathrm{n}}\right)$ and stomatal conductance $\left(\mathrm{g}_{\mathrm{s}}\right)$ in WW and WS Control $\left(\mathrm{y}=-0.12+85.75^{*} \mathrm{x}\right.$ $-148.50 * \mathrm{x}^{2}, \mathrm{R}^{2}=0.94 p<$ $0.0001)$ and $\mathrm{AN}(\mathrm{y}=-0.09+$ $74.03 * \mathrm{x}-111.45 * \mathrm{x}^{2}, \mathrm{R}^{2}=0.88 p$ $<0.0001$ ) vines (unconditioned leaves) excluding data point collected after rewatering (B)

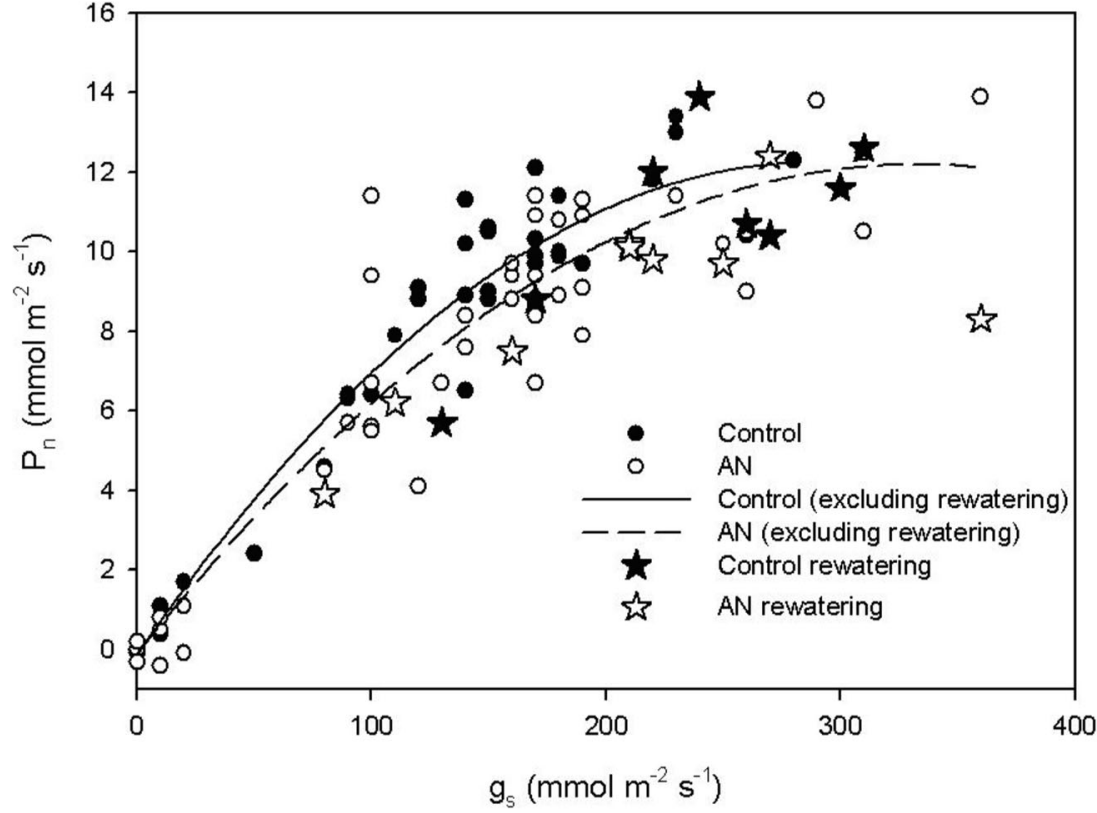

the unconditioned leaves until DOY 187 and it was higher than $\mathrm{P}_{\mathrm{n}}$ measured in horizontal Control leaves all over the experiment (Fig. 6b).

During WS (DOY 184-186), $\mathrm{g}_{\mathrm{s}}$ and $\mathrm{P}_{\mathrm{n}}$ were close to 0 in all treatments (Fig. 7a and b). After rewatering, $g_{s}$ was significantly influenced by the leaf orientation and by the interaction between leaf orientation and $\mathrm{AN}$ treatment (Fig. 7a). $\mathrm{P}_{\mathrm{n}}$ was significantly affected by leaf orientation only (Fig. 7b). Unconditioned leaves had a prompter recovery of $g_{s}$ and $P_{n}$ in comparison with horizontal leaves, reaching $\mathrm{g}_{\mathrm{s}}$ and $\mathrm{P}_{\mathrm{n}}$ values consistently lower than those recorded on the unconditioned leaves. Under WS, there was no difference between Control and AN leaves for $g_{s}$ and $P_{n}$.

$\mathrm{F}_{\mathrm{v}} / \mathrm{F}_{\mathrm{m}}$ was significantly affected by leaf orientation and $\mathrm{AN}$ treatment, and by the interaction between leaf orientation and AN treatment (Fig. 8a and $8 b$ ). $F_{v} / F_{m}$ was higher in unconditioned leaves in comparison with horizontal ones under WW condition (Fig. 8a). Horizontal leaves with the application of $\mathrm{AN}$ had higher $\mathrm{F}_{\mathrm{v}} / \mathrm{F}_{\mathrm{m}}$ values than Control horizontal leaves all over the experiment, except at DOY 186 and 189. Under WS, $\mathrm{F}_{\mathrm{v}} / \mathrm{F}_{\mathrm{m}}$ was significantly lower in horizontal leaves in comparison with unconditioned leaves without significant effect of
Fig. 5 Relationship between net plant hydraulic conductance $\left(\mathrm{K}_{\text {plant }}\right)$ and water potential at midday $\left(-\Psi_{\text {stem }}\right)$ in WW and WS Control $(\mathrm{y}=3.27 /(1+\exp (-(\mathrm{x}-$ $0.23) /-0.12, \mathrm{R}^{2}=0.73 p<$ $0.0001)$ and $\mathrm{AN}(\mathrm{y}=4.32 /(1+$ $\exp \left(-(\mathrm{x}-0.92) /-0.16, \mathrm{R}^{2}=0.76\right.$ $p<0.0001$ ) vines (unconditioned leaves) excluding data point collected after rewatering

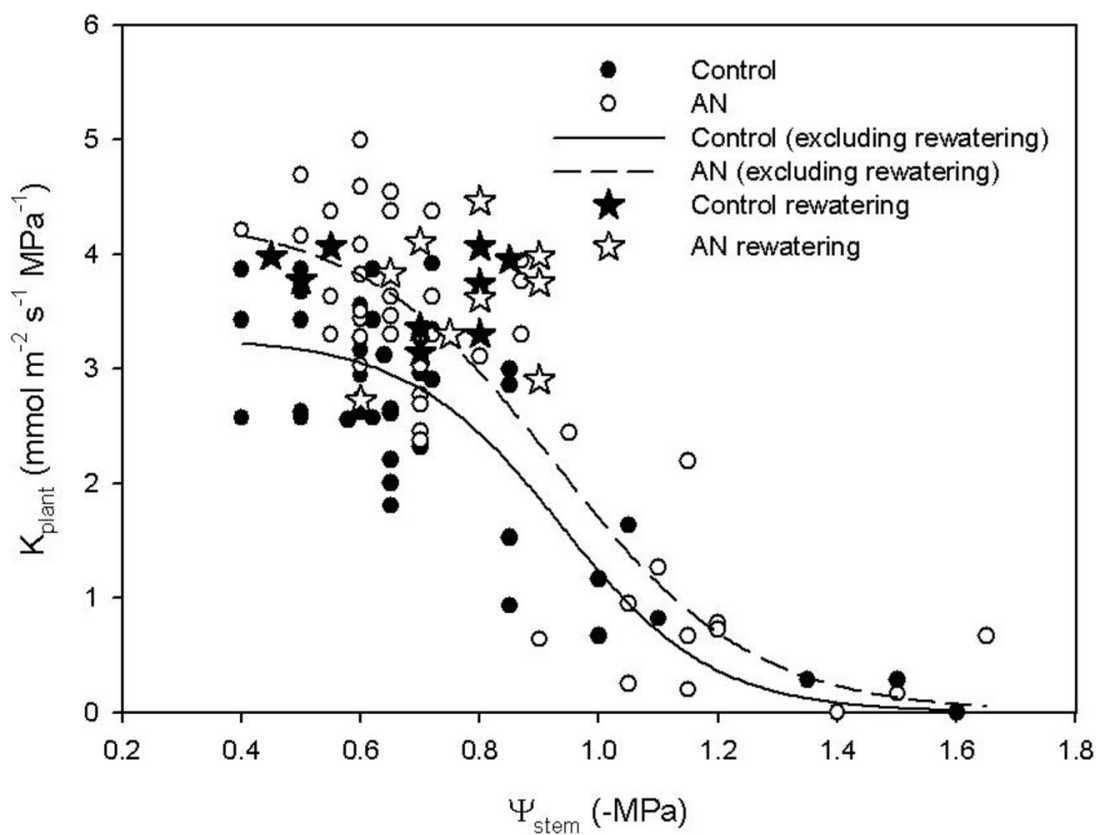


Fig. 6 Stomatal conductance $\left(\mathrm{g}_{\mathrm{s}}\right)$ (a) and net photosynthesis $\left(\mathrm{P}_{\mathrm{n}}\right)$ (b) under well-watered condition (WW) during the experiment in Control and AN leaves artificially kept horizontal and normally oriented. Each point is the mean of three vine \pm SE. Points marked by different letters are different per $p$ $<0.05$ (two-way ANOVA and Tukey test)

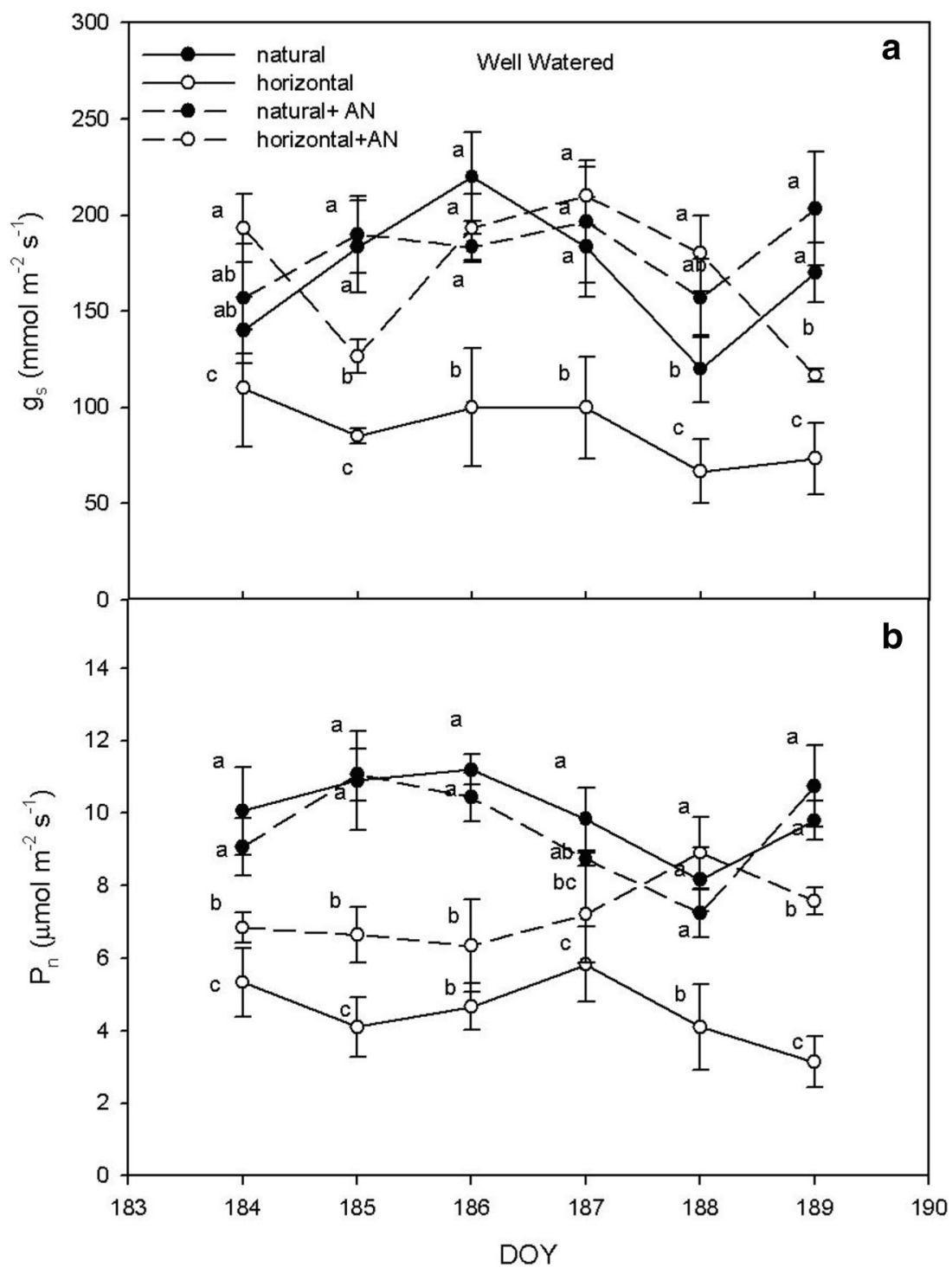

the AN extract (Fig. 8a); after rewatering, AN caused a faster recovery of $\mathrm{F}_{\mathrm{v}} / \mathrm{F}_{\mathrm{m}}$ in comparison with horizontal Control leaves.

Under WW condition, leaf temperature was significantly influenced by the leaf orientation and by the interaction between leaf orientation and AN treatment. Leaf temperature was higher in horizontal leaves when compared with unconditioned leaves at DOY 186, 187, and 189 (Fig. 9a). In unconditioned leaves, Control and AN leaves had similar values. In horizontal leaves, AN had significantly lower $\mathrm{T}_{\text {leaf }}$ than Control at DOY 185, 186, 187, and 189.

Under WS, leaf temperature was significantly influenced by the leaf orientation and by the interaction between leaf orientation and AN treatment. Horizontal leaves had higher $\mathrm{T}_{\text {leaf }}$, regardless of the treatment; on the other hand, unconditioned leaves had lower $\mathrm{T}_{\text {leaf }}$ and $\mathrm{AN}$ leaves had consistently lower $\mathrm{T}_{\text {leaf }}$ in comparison with unconditioned Control leaves (Fig. 9b). During rewatering, $\mathrm{T}_{\text {leaf }}$ gradually decreased regardless of the treatment. Horizontal leaves had a slower decrease of $\mathrm{T}_{\text {leaf }}$ in comparison with unconditioned leaves.

Transpiration was positively correlated with air VPD in unconditioned Control and AN leaves, and in horizontal AN leaves. The correlation in horizontal Control leaves was not significant ( $p=0.38$ ) (Fig. 10). Control horizontal leaves showed the least slope and the lowest average value for the regression parameter $\mathrm{E}$, while the slope for the regression for the AN treatments was higher than for the Control vines, indicating the increasing effect of VPD on E.

\section{Discussion}

During our experiment, the effect of AN extract was mild under either well-watered or water stress conditions. We tested a scale of WS conditions that ranged from mild to severe stress (i.e., minimum stomatal conductance was far below $50 \mathrm{mmol}$ 
Fig. 7 Stomatal conductance $\left(\mathrm{g}_{\mathrm{s}}\right)$ (a) and net photosynthesis $\left(\mathrm{P}_{\mathrm{n}}\right)$ (b) under water stress (WS) and after rewatering during the experiment in Control and AN leaves artificially kept horizontal and normally oriented. Each point is the mean of three vine \pm SE. Points marked by different letters are different per $p<0.05$ (twoway ANOVA and Tukey test)

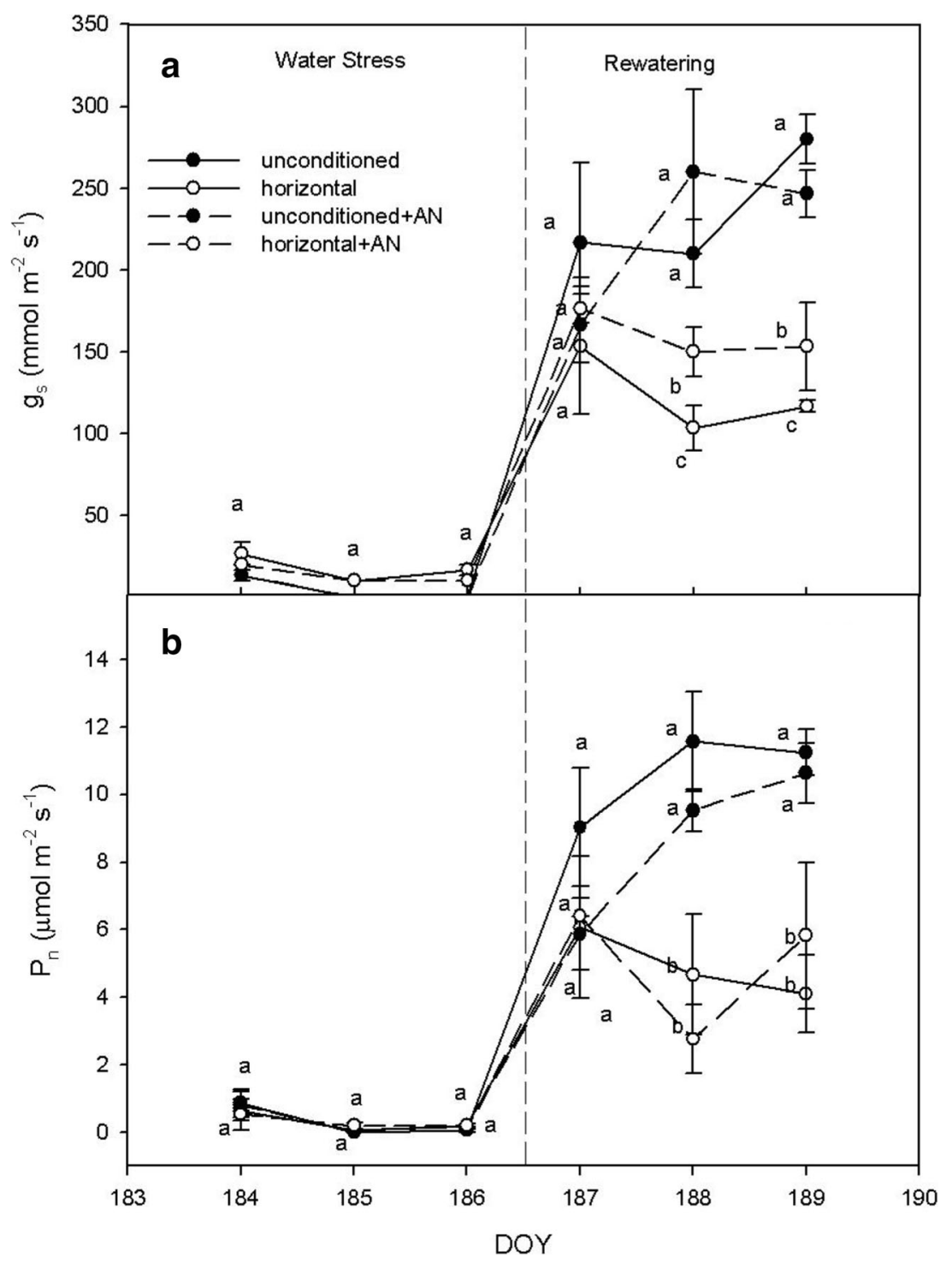

$\mathrm{m}^{2} \mathrm{~s}^{-1}$ indicated as limiting for assimilation by Flexas and Medrano (2002)). We reached complete stomata closure, and on DOY 186 we recorded leaf respiration. Noteworthy, in 2 days, and in particular during the early rewatering period, $\mathrm{AN}$ had significant higher stomatal conductance than Control, indicating a prompter resumption of physiological activity in AN-treated vine when compared to Control vines (Fig. 1). This was consistent with the higher $\mathrm{F}_{\mathrm{v}} / \mathrm{F}_{\mathrm{m}}$ recorded at DOY 186, when water stress was most severe, right before rewatering. While leaf $\Psi_{\text {pd }}$ was similar between treatments under WW and WS conditions, a more negative $\Psi_{\text {stem }}$ indicates that in AN vines the reduction of water availability in the soil was partly compensated by an increased tension in the xylem to increase water absorption from the soil at low potentials (Fig. 2) (Choné et al. 2001). Indeed, AN vines retained larger stomatal conductance between -0.8 and $-1.2 \mathrm{MPa}$ in comparison to Control vines (Fig. 3a). The larger stomatal conductance allowed a higher rate of photosynthetic activity in AN vines in contrast to the Control ones (Fig. 3b). Indeed, under water stress, stomatal conductance did not limit $\mathrm{CO}_{2}$ uptake except between DOY 183 and DOY186 in WS treatments (Fig. 1). In fact, $\mathrm{P}_{\mathrm{n}}$ was affected by $\mathrm{g}_{\mathrm{s}}$ mainly at values below $\sim 150 \mathrm{mmol} \mathrm{m}^{-2} \mathrm{~s}^{-1}$ (Fig. 4).

During recovery, $\mathrm{g}_{\mathrm{s}}$ was slightly higher in comparison with $\mathrm{g}_{\mathrm{s}}$ values recorded in the same interval of $\Psi_{\text {stem }}$ in WW treatments and during the previous WS regime (Fig. 3a). This is consistent with previous studies which have reported an increase of stomatal conductance in plants subjected to a WS condition earlier in the season or in previous years (Hochberg et al. 2017; Tombesi et al. 2018). On the other hand, $P_{n}$ rates recorded during rewatering were like those recorded at similar $\Psi_{\text {stem }}$ in WW vines and during WS. This indicates that the higher stomatal conductance in AN vines provided beneficial photosynthetic activity during recovery. However, the severe levels of water stress we reached caused a consistent decrease of $F_{v} / F_{m}$ (Fig. 1) indicating damage to leaf photosystems. 
Fig. $8 \quad \mathrm{~F}_{\mathrm{v}} / \mathrm{F}_{\mathrm{m}}$ under well-watered condition (a) and under water stress (WS) and after rewatering (b) during the experiment in Control and AN leaves artificially kept horizontal and normally oriented. Each point is the mean of three vine \pm SE. Points marked by different letters are different per $p$ $<0.05$ (two-way ANOVA and Tukey test)

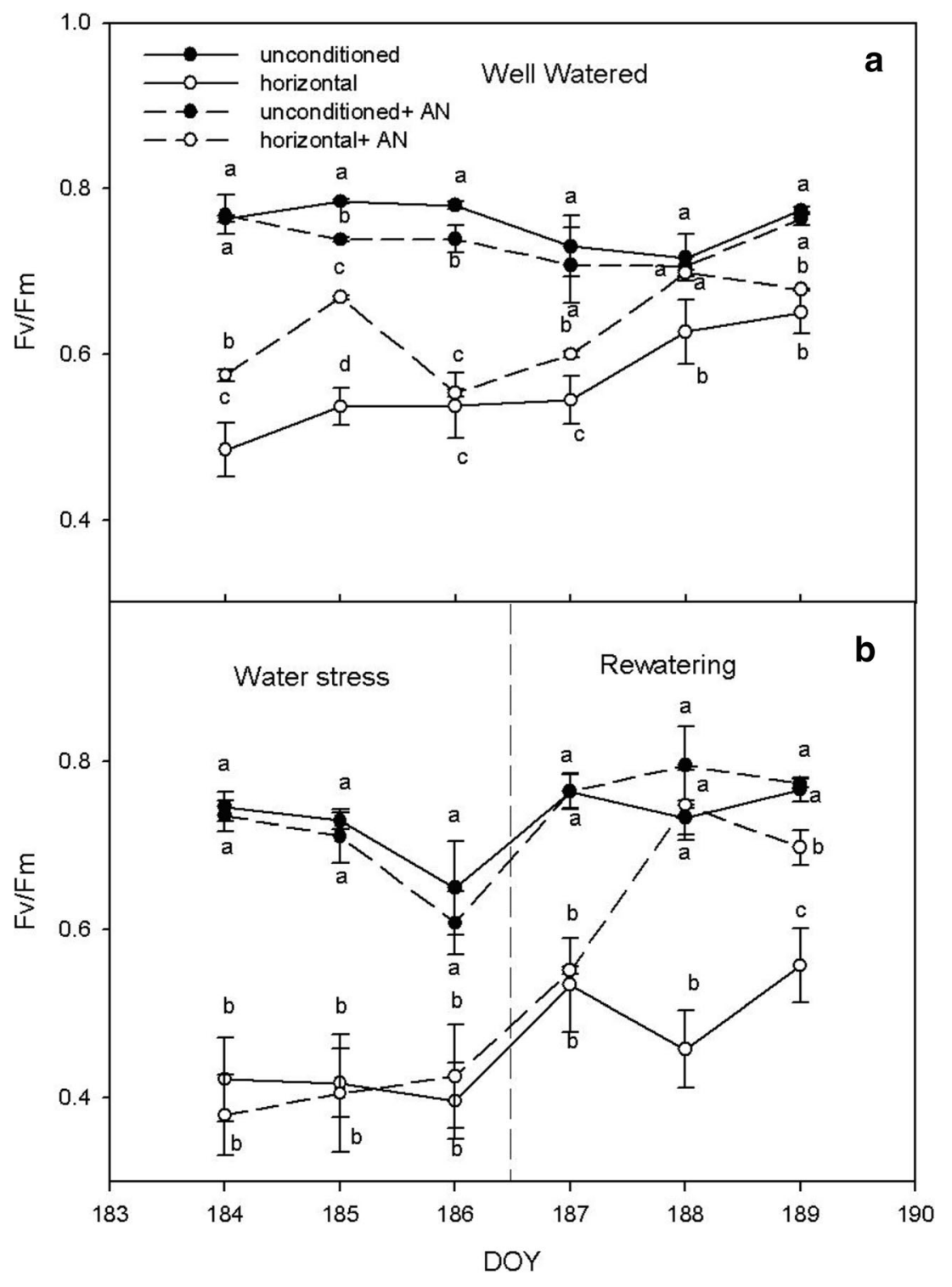

AN treatments reported larger stomatal conductance at non-limiting $\Psi_{\text {stem }}$ and under severe water stress, in agreement with the larger plant hydraulic conductance that allowed vines to transpire slightly more water (Fig. 5). This ability is important when temperature is particularly high and the amount of water available in the soil causes a severe reduction in transpiration, limiting the capacity of leaf cooling for the plant.

Under non-limiting soil water condition, larger stomatal conductance induced by AN can play a pivotal role in hot days when leaves are exposed to high solar radiation regimes. In leaves horizontally oriented, the effect of AN extract was highlighted under WW and the recovery period following the water stress: stomatal conductance was significantly reduced in horizontal leaves in comparison to unconditioned leaves (Fig. 6). Indeed, leaf transpiration (E) was limited in leaves continuously exposed to solar radiation (i.e., horizontal leaves) (Fig. 10). In fact, the excess of exposure to solar radiation caused a reduction of $\mathrm{E}$ in Control and $\mathrm{AN}$ vines. However, in AN-treated vines, E maintained the same proportional increase (i.e., indicated by the correlation slope) to increasing VPD and, in Control horizontal leaves, E did not increase to support the VPD demand. This suggests that AN reduced the stomata sensitivity to VPD that can limit transpiration at high VPD values (Cincera et al. 2019). This resulted in an increased capability for the leaf to proportionally increase thermoregulation at increasing temperatures.

The overall decrease of $E$ in leaves kept horizontal during the entire experiment can be explained by a limitation related to the leaf hydraulic conductance that was set by the condition experienced by the leaf at the leaf expansion stage (Sack and Holbrook 2006). The treatment imposed on horizontal leaves can be considered a partial simulation of the occurrence of short periods (few days) of high maximum daily temperatures during the summer. Indeed, such high temperature extremes may induce leaf 
Fig. 9 Leaf temperature $\left(\mathrm{T}_{\text {leaf }}\right)$ under well-watered condition (a) and under water stress (WS) and after rewatering (b) during the experiment in Control and AN leaves artificially kept horizontal and normally oriented. Each point is the mean of three vine $\pm \mathrm{SE}$. Points marked by different letters are different per $p<0.05$ (twoway ANOVA and Tukey test)

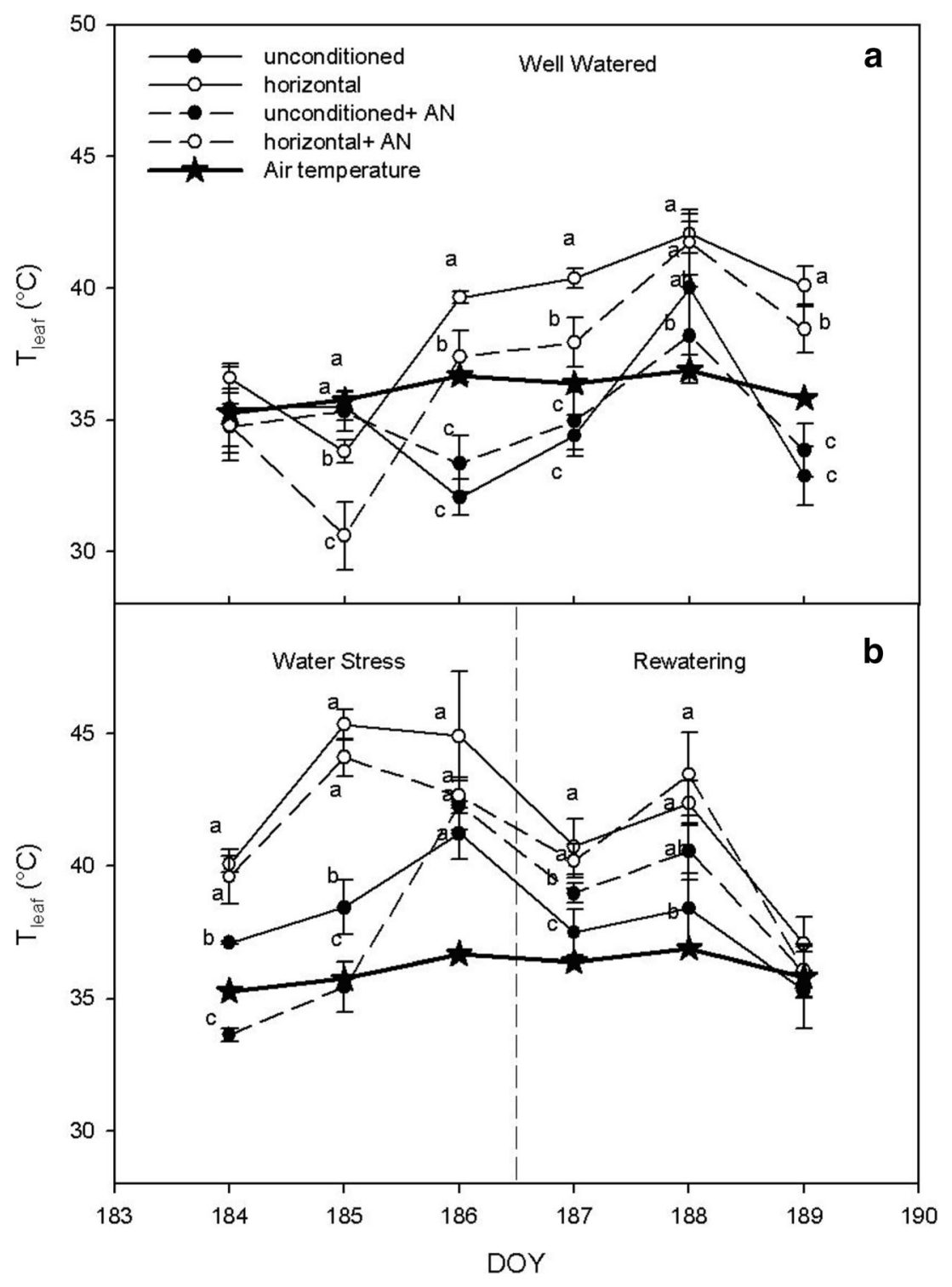

senescence in leaves formed early in the season (Chabot and Hicks 1982) under low VPD regimes, that are not capable of transpiring enough water proportionally to the increase of VPD.

Under WW conditions, $g_{s}$ was higher in AN than in Control leaves, keeping values close to those of unconditioned leaves (Fig. 6). The increased $g_{s}$ was beneficial for $P_{n}$, that in $A N$ horizontal leaves was less reduced than in Control horizontal leaves. In comparison with natural oriented leaves, in horizontal leaves, $\mathrm{P}_{\mathrm{n}}$ reduction was mainly due to the higher temperature and the reduced quantum yield efficiency of PS II induced by the constant leaf exposure to high radiation regimes.

Under WS, the effect of AN was limited, since the tension in the water conducting apparatus was very high and did not allow transpiration; on the other hand, in AN there was a consistently faster recovery of stomatal conductance in horizontal leaves in comparison to the unconditioned ones (Fig. 7). The recovery of $g_{s}$ was not followed by a proportional recovery of $\mathrm{P}_{\mathrm{n}}$; this can be conceivable considering that horizontal leaves under WS reached very low values of $F_{v} / F_{m}$, which indicates irreversible photoinhibition (Fig. 8).

In our experiment, the fast recovery of stomatal conductance and transpiration in AN horizontal leaves allowed a faster recovery of the efficiency of PSII, as suggested by the values of $F_{v} / F_{m}$ at DOY 188, similar to that of normal oriented leaves exposed to the same WS treatment (Fig. 8). Thus, AN treatment exerted its main effect on stomata conductance inducing higher transpiration when water was limited but still available in the soil. In our experiment, grapevine had a behavior similar to that of AN-treated soybean reported by Shukla et al. (2018). Our experiment emphasizes the role that higher transpiration plays in improving leaf thermoregulation. AN extract, through the altered regulation of stomata, caused a reduction in leaf temperature that was particularly significant in leaves that were artificially forced to maintain a horizontal 
Fig. 10 Correlation between leaf transpiration and air VPD in normal oriented Control leaves (y $=-2.32+0.16 \mathrm{x}, \mathrm{R}^{2}=0.39, p=$ $0.0005)$, in normally oriented AN leaves $\left(\mathrm{y}=-9.06+0.34 \mathrm{x}, \mathrm{R}^{2}=\right.$ $0.27, p=0.009)$, in horizontal Control leaves $(\mathrm{y}=1.04+0.04 \mathrm{x}$, $\left.\mathrm{R}^{2}=0.05, p=0.38\right)$ and in horizontal AN leaves $(\mathrm{y}=-8.85$ $\left.+0.31 \mathrm{x}, \mathrm{R}^{2}=0.58, p=0.0002\right)$

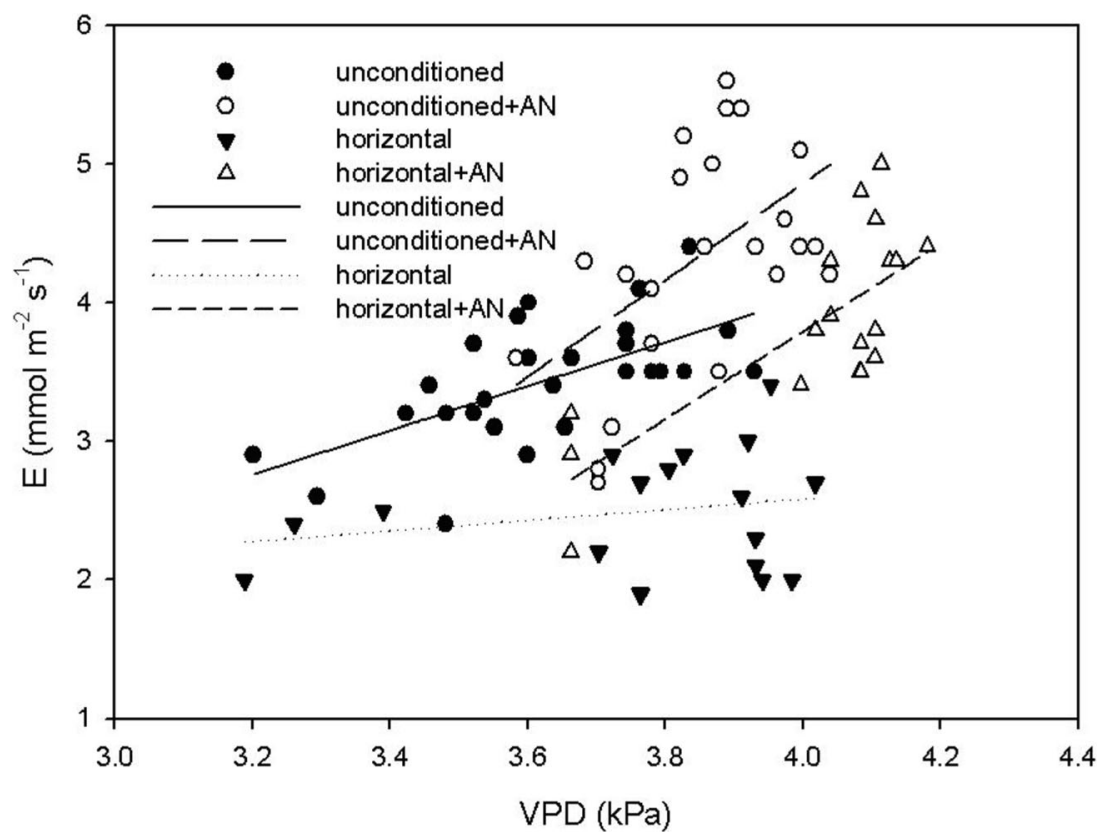

position; in these leaves, the mechanism to escape radiation by changing the incidence angle of the leaf because of wilting was excluded (Fig. 9). Our experiment was carried out at high air temperatures $\left(\sim 35^{\circ} \mathrm{C}\right)$. Under this condition, a little increase of temperature often results in the decrease of photosynthetic efficiency (Greer 2018). This can partly explain why we observed lower $P_{n}$ under well-watered condition in the horizontal leaves, when compared with unconditioned leaves. Decreased absorption of $\mathrm{CO}_{2}$ by the photosynthetic activity in combination with a larger amount of intercepted radiation represents a cost in terms of thermal dissipation, triggering a vicious loop that results in a drastic reduction of stomatal conductance. In the same way it can be interpreted the effect AN extract on unconditioned leaves: the slight increase in stomatal conductance did not report any effect on $\mathrm{CO}_{2}$ gas exchange since, under well-watered condition, $\mathrm{g}_{\mathrm{s}}$ is not a limiting factor. On the other hand, the slight increase of $g_{s}$ contributed (via the increase of E) to cooling down plant tissues, allowing the function of metabolic activities and biochemical reactions. These data suggest that $\mathrm{AN}$ extract can improve plasticity of stomata regulation dynamics at increasing levels of VPD. This contributes to minimizing long-term damage to the entire leaf photosynthetic machinery and to increasing the leaf recovery after water stress.

Recently, many efforts aimed at developing plant genotypes with a reduced stomatal density able to reduce transpiration with no effect on $\mathrm{CO}_{2}$ uptake (Bertolino et al. 2019). This is considered a viable strategy to improve crop water use efficiency and to increase the efficiency of agricultural crops in a scenario of reduced water availability (Dunn et al. 2019). Our results, even if limited to only one perennial species, highlight instead the importance of transpiration in preventing long-term damage and the role that it can play in preserving plant carbon assimilation when exposed to repeated temperature extremes.

\section{Conclusions}

AN extract increased plant hydraulic conductivity to atmosphere under a well-watered condition and at different levels of water stress by increasing stomatal conductance which was less sensitive to high VPD, in comparison with Control. The increase of transpiration allowed increasing the leaf cooling capacity during water stress that resulted in a faster recovery of photosynthesis once the availability of water was restored. In conclusion, AN extract can be an alternative and sustainable management tool to reduce the impact of short periods of high temperature and high light irradiance under well-watered conditions and it is also able to encourage a prompt photosynthetic recovery after water stress periods.

Acknowledgements Open access funding provided by Università Cattolica del Sacro Cuore within the CRUI-CARE Agreement.

Funding This work was partially supported by Acadian Seaplants Limited (Dartmouth, NS, Canada) and Biogard division (Grassobbio, BG, Italy).

\section{Compliance with ethical standards}

Conflict of interest The authors declare that they have no conflict of interest.

Open Access This article is licensed under a Creative Commons Attribution 4.0 International License, which permits use, sharing, adaptation, distribution and reproduction in any medium or format, as long as you give appropriate credit to the original author(s) and the source, 
provide a link to the Creative Commons licence, and indicate if changes were made. The images or other third party material in this article are included in the article's Creative Commons licence, unless indicated otherwise in a credit line to the material. If material is not included in the article's Creative Commons licence and your intended use is not permitted by statutory regulation or exceeds the permitted use, you will need to obtain permission directly from the copyright holder. To view a copy of this licence, visit http://creativecommons.org/licenses/by/4.0/.

\section{References}

Bertolino LT, Caine RS, Gray JE (2019) Impact of stomatal density and morphology on water-use efficiency in a changing world. Front Plant Sci 10:225

Chabot BF, Hicks DJ (1982) The ecology of leaf life spans. Ann Rev Ecol Systemat 13:229-259

Choné X, Van Leeuwen C, Dubourdieu D, Gaudillère JP (2001) Stem water potential is a sensitive indicator of grapevine water status. Ann Bot 87:477-483

Cincera I, Frioni T, Ughini V, Poni S, Farinelli D, Tombesi S (2019) Intra-specific variability of stomatal sensitivity to vapour pressure deficit in Corylus avellana L.: a candidate factor influencing different adaptability to different climates? J Plant Physiol 232:241-247

De Pascale S, Rouphael Y, Colla G (2017) Plant biostimulants: innovative tool for enhancing plant nutrition in organic farming. Eur J Hort Sci 82:277-285

Di Stasio E, Van Oosten MJ, Silletti S, Raimondi G, dell' Aversana E, Carillo P, Maggio A (2018) Ascophyllum nodosum-based algal extracts act as enhancers of growth, fruit quality, and adaptation to stress in salinized tomato plants. J Appl Phycol 30:2675-2686

du Jardin P (2015) Plant biostimulants: definition, concept, main categories and regulation. Sci Hortic 196:3-14

Dunn J, Hunt L, Afsharinafar M, Al Meselmani M, Mitchell A, Howells R, Wallington E, Fleming AJ, Gray JE (2019) Reduced stomatal density in bread wheat leads to increased water-use efficiency. J Exp Bot 70:4737-4748

Faurie B, Cluzet S, Corio-Costet MF, Mérillon JM (2009) Methyl jasmonate/ethephon cotreatment synergistically induces stilbene pro-duction in Vitis vinifera cell suspensions but fails to trigger resistance to Erysiphe necator. J Int Sci Vigne Vin 43:99-110

Flexas J, Medrano H (2002) Drought-inhibition of photosynthesis in C3 plants: stomatal and non-stomatal limitation revisited. Ann Bot 89: 183-189

Frioni T, Sabbatini P, Tombesi S, Norrie J, Poni S, Gatti M, Palliotti A (2018) Effects of a biostimulant derived from the brown seaweed Ascophyllum nodosum on ripening dynamics and fruit quality of grapevines. Sci Hortic 232:97-106

Frioni T, Tombesi S, Quaglia M, Calderini O, Moretti C, Poni S, Gatti M, Moncalvo A, Sabbatini P, Berrìos JG, Palliotti A (2019) Metabolic and transcriptional changes associated with the use of Ascophyllum nodosum extracts as tools to improve the quality of wine grapes (Vitis vinifera cv. Sangiovese) and their tolerance to biotic stress. J Sci Food Agric 99:6350-6363

Greer DH (2018) Canopy growth and development processes in apples and grapevines: responses to temperature. Hortic Rev 45:313-369

Hochberg U, Bonel AG, David-Schwartz R, Degu A, Fait A, Cochard H, Peterlunger E, Herrera JC (2017) Grapevine acclimation to water deficit: the adjustment of stomatal and hydraulic conductance differs from petiole embolism vulnerability. Planta 245:1091-1104
IPCC (2013) Summary for policymakers. In: Stocker TF, Qin D, PlattnerG-K, Tignor M, Allen SK, Boschung J, Nauels A, Xia Y, Bex V, Midgley PM (eds.) Climate change 2013: the physical science basis. Contribution of Working Group I to the Fifth Assessment Report of the Intergovernmental Panel on Climate Change. Cambridge University Press, Cambridge

Jayaraman J, Norrie J, Punja ZK (2011) Commercial extract from the brown seaweed Ascophyllum nodosum reduces fungal diseases in greenhouse cucumber. J Appl Phycol 23:353-361

Khan W, Rajirath UP, Subramanian S, Jithesh MN, Rayorath P, Hodges DM, Critchley AT, Craigie JS, Norrie J, Prithiviraj B (2009) Seaweed extracts as biostimulants of plant growth and development. J Plant Growth Regul 28:386-399

Laetitia A, Fauchon M, Blanc N, Hauchard D, ArGall E (2010) Phenolic compounds in the brown seaweed Ascophyllum nodosum: distribution and radical-scavenging activities. Phytochem Anal 21:399-405

Norrie J, Branson T, Keathley PE (2002) Marine plant extracts impact on grape yield and quality. Acta Hortic 594:315-319

Popescu GC, Popescu M (2014) Effect of the brown alga Ascophyllum nodosum as biofertilizer on vegetative growth in grapevine (Vitis vinifera $\mathrm{L}$ ). Curr Trends Nat Sci 3:61-67

Raza A, Razzaq A, Mehmood SS, Zou X, Zhang X, Lv Y, Xu J (2019) Impact of climate change on crops adaptation and strategies to tackle its outcome: a review. Plants 8:2-29

Sabir A, Yazar K, Sabir F, Kara Z, Yazici MA, Goksu N (2014) Vine growth, yield, berry quality attributes and leaf nutrient content of grapevines as influenced by seaweed extract (Ascophyllum nodosum) and nanosize fertilizer pulverizations. Sci Hortic 175:1-8

Sack L, Holbrook NM (2006) Leaf hydraulics. Annu Rev Plant Biol 57: 361-381

Salvi L, Brunetti C, Cataldo E, Niccolai A, Centritto M, Ferrini F, Mattii GB (2019) Effects of Ascophyllum nodosum extract on Vitis vinifera: consequences on plant physiology, grape quality and secondary metabolism. Plant Physiol Biochem 139:21-32

Salvi L, Brunetti C, Cataldo E, Storchi P, Mattii GB (2020) Ecophysiological traits and phenylpropanoid profiling on potted Vitis vinifera $\mathrm{L}$. cv Pinot noir subjected to Ascophyllum nodosum treatments under post-veraison low water availability. Appl Sci 10:4473

Shukla PS, Shotton K, Norman E, Neily W, Critchley AT, Prithiviraj B (2018) Seaweed extract improve drought tolerance of soybean by regulating stress-response genes. AoB Plants 10:plx051

Shukla PS, Mantin EG, Adil M, Bajpai S, Critchley AT, Prithiviraj B (2019) Ascophyllum nodosum-based biostimulants: sustainable applications in agriculture for the stimulation of plant growth, stress tolerance, and disease management. Front Plant Sci 10:655

Sperry JS, Pockman WT (1993) Limitation of transpiration by hydraulic conductance and xylem cavitation in Betula occidentalis. Plant Cell Environ 16:279-287

Strasser RJ, Srivastava A, Govindjee (1995) Polyphasic chlorophyll $a$ fluorescence transient in plants and cyanobacteria. Photochem Photobiol 61:32-42

Tombesi S, Frioni T, Poni S, Palliotti A (2018) Effect of water stress "memory" on plant behavior during subsequent drought stress. Environ Exp Bot 150:106-114

Yakhin OI, Lubyanov AA, Yakhin IA, Brown PH (2017) Biostimulants in plant science: a global perspective. Front Plant Sci 7:2049

Publisher's note Springer Nature remains neutral with regard to jurisdictional claims in published maps and institutional affiliations. 